\title{
Reflexões sobre a aplicação da Lei 10.639/03 em escolas da zona oeste do Rio de Janeiro e Baixada Fluminense ${ }^{1}$
}

\author{
Reflexiones sobre la aplicación de la ley 10.639 / 03 en \\ escuelas de la zona oeste del Rio de Janeiro y bajada Fluminense
Reflections about the aplication of the 10.639/03 law in Rio de Janeiro's west zone and Fluminense lowland's schools

\author{
Monica Regina Miranda²
}

\begin{abstract}
Resumo
Essa abordagem visa evidenciar as especificidades e problemáticas geradas na implementação da Lei Federal 10.639/03, que versa sobre o ensino da história e cultura afro-brasileira e africana no currículo oficial da rede de ensino brasileira, em sua prática cotidiana. Neste contexto, o presente trabalho procura dar concretude ao problema de pesquisa sobre: a valorização da educação e os obstáculos de aplicação da lei 10.639/03 no sistema educacional básico, sendo a etnografia feita em quatro CIEP's (Centros Integrados de Escolas Públicas) da Zona Oeste do Rio de Janeiro e da Baixada Fluminense, no ano de 2014/15. A partir da realização de entrevistas e da prática da observação participante, verificou-se que a aplicabilidade efetiva da lei em questão está diretamente relacionada com uma série de fatores existentes nas práticas dos atores presentes na esfera educacional (professores, diretores, pedagogos etc.) e de seus posicionamentos em relação à contribuição do negro à cultura afro-brasileira. Neste sentido, as relações étnico-raciais foram demarcadores primordiais para a compreensão, não somente das análises, mas como do objeto de estudo em si.
\end{abstract}

Palavras-Chave: Raça, Racismo, Lei 10.639/03, Identidade racial, Espaço escolar.

\section{Resumen}

Este enfoque pretende evidenciar las especificidades y problemáticas generadas en la implementación de La Ley Federal 10.639 / 03, que trata sobre la enseñanza de la historia y cultura afrobrasileña y africana en el currículo oficial de la red de enseñanza brasileña, en su práctica cotidiana. En este contexto, el presente trabajo busca concretar el problema de investigación sobre: la valorización de la educación y los obstáculos de aplicación de la ley 10.639 / 03 en el sistema educativo básico, siendo la etnografía hecha en cuatro CIEP (Centros Integrados de Escuelas Públicas) en el oeste de Río de Janeiro y de la Baixada Fluminense, en los años 2014/15. A partir de la realización de entrevistas y de la práctica de la observación participante, se verificó que la aplicabilidad defectiva de la ley en cuestión está directamente relacionada con una serie de factores existentes en las prácticas de los actores presentes en la esfera educativa (profesores, directores, pedagogos- etc.) y de sus posicionamientos en relación a la contribución del negro a la cultura afrobrasileña. En este sentido, las relaciones étnico-raciales fueron demarcadores primordiales para la comprensión, no sólo de los análisis, sino del objeto de estudio en sí.

Palabras claves: Raza, Racismo, Ley 10.639 / 03, Identidad racial, Espacio escolar.

1 Artigo apresentado no Simpósio Temático "Integração e Multiculturalismo na América Latina: Perspectiva histórica e desafios no contexto atual" durante o II Seminário Latino-Americano de Estudos em Cultura - SEMLACult em Foz do Iguaçu/PR, Brasil, 2018.

2 Mestranda em Antropologia pela Universidade Federal Fluminense (PPGA/UFF). Cientista Social pela Universidade Federal Rural do Rio de Janeiro (UFRJ). Rio de Janeiro/RJ, Brasil. pesquisadoramonicamiranda@gmail.com. 


\begin{abstract}
This approach aims to highlight the specificities and problems generated in the implementation of Federal Law $10.639 / 03$, which deals with the teaching of Afro-Brazilian and African history and culture in the official curriculum of the Brazilian education network, in its daily practice. In this context, the present work seeks to concretize the research problem on the valuation of education and the obstacles of application of law 10.639/03 in the basic educational system. The ethnography took place in four CIEP's (Integrated Centers of Public Schools) of the west zone of Rio de Janeiro and Baixada Fluminense, in the years 2014/15. From the interviews and the practice of participant observation, it was verified that the effective applicability of the law in question is directly related to a series of factors existing in the practices of the actors present in the educational cenario (teachers, directors, pedagogues, etc.) and their positioning in relation to the contribution of the black people to afro-brazilian culture. In this sense, ethnic-racial relations were primordial paths for the understanding, not only to the analyzes, but as of the object of study itself.
\end{abstract}

Key words: Race, Racism, Law 10.639 / 03, Racial identity, Educational space.

\title{
1. Contextualização
}

Em abordagem que visa evidenciar especificamente os entraves tanto na implementação da lei 10.639/03 quanto na sua prática cotidiana, o presente trabalho também procura dar concretude à um olhar sobre a importância da valorização de uma educação antirracista no sistema educacional básico. Num primeiro momento a pesquisa que resultou nesse artigo verificou que a aplicabilidade da lei possui relação direta com uma sensibilidade e conscientização dos atores sociais presentes nas instituições de ensino (professores, diretores, pedagogos, etc.) com relação a contribuição do negro à cultura afro brasileira. Neste sentido, os processos inter e intra sociais foram os principais demarcadores para a compreensão não somente das análises realizadas, mas, sobretudo do objeto de estudo em questão.

A história do povo negro e seus descendentes no Brasil é permeada de obstáculos que prejudica quaisquer chances reais de ascensão social. Desde o período escravocrata as nossas instituições, sejam públicas ou privadas, cria efetivos mecanismos de dominação que submete a população negra a um regime de perversidade, e como bem sabemos no âmbito educacional não poderia ser diferente. No entanto, com o decorrer do tempo a realidade do acesso à educação foi modificado com a aplicação e implementação de políticas públicas. Uma mola propulsora que possibilitou e possibilita a entrada de pessoas negras dentro do sistema público de ensino e afeta o percentual de maneira positiva. Desta forma, o país passa a ver um número crescente de afrodescendentes ocupando cadeiras em instituições de ensino federais e universidades públicas. 
A importância de se ter mais negros dentro do sistema de ensino está diretamente relacionada com a necessidade de diminuir as barreiras sociais e criar pontes de oportunidades para esta população. Os Parâmetros Curriculares Nacionais (PCNs) são um conjunto de pareceres da educação básica nacionais que discorrem sobre uma variedade de assuntos, e um deles se refere a obrigatoriedade de uma educação que respeite e compreenda em suas premissas, as nuances e particularidades culturais e sociais brasileiras. Ciente, também dos mecanismos de representatividade que compõem a estrutura societária, e que efetivamente consiga abarcar a todos.

Neste sentido a inserção não somente contribui para a elevação do conhecimento em ampla escala. Mas como contribui para o equilíbrio da estrutura social do país. Diante disso o que se apresenta como desafio de pesquisa é a análise das possíveis barreiras que dificultam a implementação objetiva da lei 10.639/03, referente a inclusão dos conteúdos de história e cultura africana e afro-brasileira nos currículos escolares das instituições de ensino públicas e privadas.

Ainda que já sancionada, a existência real da lei depende do voluntarismo, da sensibilidade e da empatia do corpo docente com a temática. Apesar da presença extensa de investimentos institucionais como prêmios, políticas públicas, presença de material didático e paradidático; observa-se, ainda uma grande resistência no aprofundamento das práticas pedagógicas. Desse modo, o precípuo objetivo é perceber os obstáculos que não são vistos de maneira concreta em função do mito da democracia racial.

A lei já se encontra sancionada e já se dispõe de material para sua aplicação e no entanto boa parte das escolas ainda não se ajustaram aos seus termos. O que nos coloca diante de um ponto de interrogação e nos faz buscar uma resposta, na medida em que se compreende que esse fenômeno está diretamente relacionado com as formas de articulação do racismo no Brasil. Sobretudo em seu caráter institucional, e a maneira como a desigualdade sóciorracial se manifesta no âmbito educacional.

Entende-se que a não prática sistemática da lei implica em problemas de ordem social e psíquica: como a baixa autoestima, negação da própria imagem, sentimentos de angústia e revolta; dificuldades de relacionamento e queda no rendimento escolar por parte dos estudantes negros. A vista disso, o espaço escolar abre possibilidades apenas em datas comemorativas e feriados nacionais para reflexão sobre questões ligadas a temática étnico- 
racial, em contraposição se observa uma plena ausência da discussão no resto de ano letivo.

$\mathrm{O}$ atual trabalho nasce da necessidade basilar de um entendimento mais aprofundado dos debates decorrentes dos 10 anos da lei 10.639/03 e da sua dificuldade de implementação. Sendo assim, optou-se por estudar os principais fatores que possuem desdobramento da ausência prática efetiva no sistema educativo. Os docentes da educação básica após um farto e longo debate, referente a aplicabilidade da lei, descreveram os problemas ao aplicar a mesma. Através desse diálogo inicial houve uma aproximação da pesquisadora nas respectivas instituições educativas: CIEP-168 312, Colégio Raul Ryff, Colégio Municipal Alberto Filho.

Com o intuito de buscar as causas que impedem a lei seja aplicada ou não. As experiências em campo possibilitaram avaliar importantes questões sobre o racismo e desigualdades no espaço escolar.

Neste sentido, a superação das relações raciais assimétricas depende do resgate da história do negro e da conscientização dos discentes e docentes sobre a importância, respeito e igualdade de se falar dessa genealogia. Dentro desta perspectiva, a legislação é encarada como uma das importantes ferramentas de sobrepujamento dos entraves sociais. Portanto, a análise feita se estende na compreensão deste processo que faz com que haja muralhas a serem ultrapassadas na efetiva implementação da lei.

A inclusão dos conteúdos de historia da África e Cultura Afrodescente nos currículos nacionais carecem ser dadas ao improviso, ou seja, torna-se necessário a conconcomitancia de ações pedagogícas em conjunto com gestores, professores e os agentes escolares? para a formulação de pratícas educativas que realmente contemplem as exigências da lei 10.639/03. A metodologia empregada na pesquisa se deu por meio de entrevistas abertas com dez professores e professoras, em seis escolas da rede pública estadual do Rio de Janeiro, bem como na análise dos contextos escolares por intermédio da observação participante nas quais os referidos professores e professoras estão inseridos. As entrevistas foram realizadas com docentes das disciplinas de Língua Portuguesa, História e Biologia; tendo em vista perceber não apenas as formas como esses conteúdos foram inseridos em suas práticas pedagógicas, mas, todavia, entender as representações dos professores sobre as possibilidades e impossibilidades da lei. Nas escolas em que foram realizadas as pesquisas de campo verificou-se a existência de materiais referente a lei 10.639/03, o que não corrobora, todavia, com a ideia tangente da inexistência de esforços na implementação de tais medidas sóciopedagógicas. No mês de Novembro nota-se um acréscimo nas atividades galgadas na temática étnico-racial, se comparado com o restante do ano letivo. Percebe-se, ainda que 
mediante as possibilidades devem ser desenvolvidas estratégias para mudar este cenário, com construção de processos pedagógicos que visam reverter o quadro da discriminação e do preconceito racial no Brasil e na manutenção do processo de construção da identidade do negro.

\section{I - A problematização da lei $\mathbf{1 0 . 6 3 9 / 0 3}$}

A lei 10.639/03 precisa ser lida e interpretada sob o prisma que nos coloca diante de muralhas no sistema de ensino básico brasileiro. Conscientizar é a melhor forma de sairmos da esfera da simples implementação voluntarista e recorrente. Precisa-se, para além desta conscientização, um exercício de problematização por parte dos profissionais da área de educação, na qual se faz necessária uma discussão como se ensina, para que se ensina e o que é ensinado. Os professores, gestores e agentes de educação precisam compreender e entender que os conteúdos partilhados na escola surtem efeitos de médio a longo prazo no seu alunado.

\section{1 - A compreensão da lei 10.639/03}

A valorização do negro perpassa na construção da identidade e do reconhecimento da cultura afro brasileira e de sua história como indispensáveis para a formação histórica do Brasil. Estudar as diferentes matrizes culturais dos povos que aqui estiveram produz uma priorização de pertencimento pessoal, social, psíquico e identitário de pessoas negras.

A lei determina que seja inserida na LDB (lei 9.394/96) e nos currículos oficiais da rede de ensino, conteúdos sobre "História e Cultura Africana e afro-Brasileira". O que isto quer dizer, que a história e a cultura afro-brasileira podem estar inclusas em quaisquer disciplinas, porém devem ser enfatizadas nas disciplinas de educação artística, história e de literatura.

Portanto, quando a lei 10639/03 diz que deve ser expressar a contribuição positiva e a luta do povo negro em todas as áreas, seja sociais, econômicas e políticas. Anseia com isto que o negro afro brasileiro tenha a mesma igualdade social e racial do branco europeu na construção da história do Brasil. Essa solicitação na lei é relevante na medida que o negro afro-brasileiro precisa de uma valorização da "cultura negra".

Em outras palavras a lei objetivamente procura dialogar pelo processo do conhecimento e a valorização do negro e a divulgação de sua contribuição como a língua, a escrita, os sistemas simbólicos, a cosmovisão, a genealogia histórica. Desse modo, a lei permite a interação com a diversidade étnica e colabora com a desmistificação de alguns preconceitos referentes ao negro. 
A inserção da lei dentro dos espaços escolares ajuda na compreensão dos alunos negros na construção da identidade. Os agentes escolares e professores possuem uma contribuição muito importante, pois são eles que vão inserir a lei 10.639/03 para esses alunos negros e não negros. Vão apresentar a importância da historicidade e do papel civilizador deste povo. A ver o veto:

Altera a Lei $\mathrm{n}^{\circ}$ 9.394, de 20 de dezembro de 1996, que estabelece as diretrizes e bases da educação nacional, para incluir no currículo oficial da Rede de Ensino a obrigatoriedade da temática "História e Cultura Afro-Brasileira", e dá outras providências.

O Resgate da história nos permite não só compreender o presente como a possibilidade de mudar o futuro, ou seja, através do conhecimento do passado é que se compreende os fatos sociais da atualidade, como o racismo institucional. Segundo o historiador Joseph Kizerbo (1970): “Um povo sem história e como um indivíduo sem memória, um eterno errante".

\section{2 - O que a lei propõe}

A lei propõe que não necessariamente seja seguida uma única forma de ensino como regra, o que ela propõe que seja dada a valorização, contribuição do negro na sociedade brasileira, que pode ser implementada ações, que acrescente uma forma de ensino, possa ser reformulada sempre que houver necessidade. Nesse caso cabe ao Estado e a sociedade civil dar importância e elaborar políticas que divulguem e transformem o intelecto crítico, sendo incentivado na cultura, economia ou política. O ensino de história Afro-Brasileira e da África, agregam conteúdos de disciplinas em especial, história, literatura e artes plásticas, as atividades poderão ser feitas dentro ou fora da escola, ou seja, nos laboratórios de informática, bibliotecas, quadras de esportes e etc. Sempre respeitando as iniciativas das personalidades e organizações negras. Incluindo a história dos quilombos, e de remanescentes do quilombo, e de datas significativas. No que tange o ensino de história da África não é cabível tratar somente as mazelas que atingem o continente, necessário se faz, porém, um resgate de suas ancestralidades e particularidades. A legislação deve ser trabalhada e fiscalizada para garantir políticas sociais que acabem com as distorções históricas dentro do âmbito escolar e fora.

\section{3 - A construção da lei e sua emergência}

A lei vem para regular, estimular e valorizar a diversidade étnico-racial. Só que na construção social de vários agentes da educação trabalhar e falar do negro e de sua historicidade entre os alunos é pejorativo. Alguns chegam a alegar que não há distinção entres 
raças, pois todos somos pertencentes a "raça humana". Todavia o movimento social negro compreende que exaltar não somente a gênese, mas como a cosmogonia dos africanos e seus descendentes é construir alicerces positivos e possibilitar formas de empoderamento para a população negra.

Historicamente o movimento negro desde meados dos anos 70 vem se articulando com essa discussão sobre quem somos e para onde vamos, se não soubermos de onde viemos não saberemos para onde ir. Eis a questão? Foi quando perceberam que ascensão social do negro perpassa pela educação, algumas lideranças do movimento negro vão defender a tese que a questão histórica dentro da estrutura do racismo, tem uma lógica que passa pelo pressuposto da lei do ventre livre, quando os senhores se isentavam da responsabilidade social e econômica da criança, filho do escravo, já que ele nasce livre e ausente dos direitos civis.

Esse debate foi se prolongando ao longo do tempo para outras temáticas sobre o negro, racismo, desigualdades raciais, trabalho, mulher negra, política internacional, cultura negra e a educação, a partir daí dentro de suas agendas de reivindicações a educação passou ser pauta questão relevante por parte do movimento negro, eis algumas ações que foram desenvolvidas. Entre os dias 26 de agosto a 04 de setembro de 1950 aconteceu o primeiro congresso negro brasileiro com iniciativa do TEN (teatro experimental negro) fundado por Abdias do Nascimento, a partir desse congresso as ações se intensificaram na esfera da educação.

Em 1978 os movimentos sociais, pediam mais políticas públicas em suas agendas, entre 26 e 27 de agosto de 1986 na Convenção Nacional do Negro Pela Constituinte em Brasília, em 1988 foi redigida implementada a lei de criminalização ao racismo, em 20 de Novembro de 1995 houve a Marcha Zumbi dos Palmares contra o Racismo, pela Cidadania e a Vida e de contrapartida exigindo uma reparação junto ao governo nos anos seguintes.

A parti de então, se instauram e implementam as primeiras políticas públicas no governo do presidente Fernando Henrique Cardoso, mas foi no governo do presidente Lula que as políticas públicas avançaram, no decorrer do processo foi sancionada e implementada a lei 10.639/03. (Silva, 2012)

\subsection{A ESCOLA}

A escola é um sistema de aprendizado de conhecimentos e de valores onde é pertinente assegurar a variedade normativa de ensino que é reconhecer como os alunos não negros tratam os alunos negros com comentários sobre sua pele, textura do cabelo ou suas feições. Sabemos que as relações étnico-raciais, se dão fora também do âmbito escolar, porém entendemos que a maior parte do tempo esse aluno passa na escola, e como a escola é um 
instrumento difusor de opiniões, práticas pedagógicas e produção conhecimento torna-se fundamental pensar em metodologias educativas que operem na valorização do alunado negro e sua história(ancestralidade).

Ou seja, a escola atua na divulgação dos saberes, contudo, carece no que condiz a uma prática pedagógica, na qual a pluralidade cultural seja explorada, e um dos fatores que desencadeiam esta ação dentro do sistema educacional é referente às leis aprovadas em âmbito nacional nos PDNs e DCNs que contribuem diretamente para a formação ética, política, social, econômica e psicológicas de crianças e adolescentes negros.

A finalidade do plano é procurar melhorias na política de ações afirmativas tanto para os docentes e discentes, na esfera educacional, garantindo direitos aos negros e negras, acesso a todas modalidades de ensino, e melhorias nas infra- estruturas da escola, tantos para os agentes da educação como para os alunos.

O parecer vem com mais um instrumento para compreensão da lei, há uma preocupação no parecer, que é esmiuçar os conceitos para aqueles que trabalham com essas temáticas que vão servir de disseminadores das relações étnico-raciais.

No que tange ao diálogo sobre a obrigatoriedade e não opção pela implementação de uma lei educacional, é plausível que a negligência das bases educacionais ocorre por três fatores chaves: a não representação social de negros nas secretarias de educação, a naturalização histórica do processo de escravização do negro e o não querer uma prática pedagógica que proporcione uma produção de conhecimento aonde os discentes possam ter bases sólidas para dialogar e até não legitimar certos discursos.

A história há pelo menos quinhentos anos vem sendo contada diante de faces de único prisma. O que se tratando do país que possui a maior população negra fora do continente africano a invisibilidade é presente de maneira sútil ou hostil no Brasil e não somente toda a produção de conhecimento.

Com isso houve um apagamento catastrófico quando encadeamos nosso pensamento para gerações. A norte americana e professora do ciclo básico Bell Hooks em seu livro “Transgredindo a Educação: a educação como prática de liberdade”, nos afirma claramente em seu depoimento da infância até a fase adulta a maneira como a mentalidade de pessoas brancas era cruel em relação a pessoas pretas. E a mesma sentiu isso de forma mais avassaladora até quando passou a ocupar a cadeira de professora.

Bell Hooks (1994) nos deixa bem claro o quanto que a consciência histórica do racismo pode ser perversa à vida de africano e afro descentes, e a exemplo disto temos a Apartheid (África do Sul), O Mito da ideologia da democracia racial (Brasil) e o Genocídio de 
descendentes negros que ocorre em todo o mundo. Os temas mais contemporâneos influenciados pelo pluralismo cultural, necessitam de reflexão.

Assim sendo a participação da escola nesse processo é de uma suma importância já que na escola é um espaço onde se produz e reproduz o preconceito depois da família, que permeia a sociedade. Diante disso, a escola estabelece relações e interage com o processo de construção das identidades étnico-raciais. Nesse jogo de relações onde se constroem identidades, a escola torna- se um agente facilitador do debate sobre racismo e discriminação racial. Partindo do princípio que a escola é um espaço que tem como fundamento produzir e fomentar conhecimentos.

\section{II - O debate teórico sobre a lei 10.639/03}

O problema ou conflito está como a legislação dentro do âmbito escolar, fazer a lei ser implementada sem que precise passar pelo clivo do folclore ou da banalização do racismo institucional. Muitos dos profissionais da educação acham que não mencionar ou refletir sobre a questão do racismo pode gerar conflito no espaço escolar, é uma forma mais fácil de atenuar o problema do racismo. Se algum aluno faz um comentário racista em relação ao outro aluno, a reação de alguns profissionais e de banalizar a situação, pois na realidade alguns desses agentes ou professores desconhece ou finge não existir o racismo institucional.

De que forma poderemos sancionar essa brecha na legislação, já que a lei não estabelece metas para a função da lei e nem qualificação desses agentes da educação? A não viabilização da lei dentro da esfera escolar, a obrigação e o uso torna-se a legislação inócua. Sem alcance do principal objetivo que é a lei funcionar no ano letivo inteiro e não só nas datas festivas e fazer da escola um espaço democrático.

A legislação, o parecer já temos, o espaço escolar precisa e de executa- lá para diminuir o racismo, preconceito e a discriminação racial. Alguns equívocos dentro do debate nas relações raciais que faz compreender o dilema da legislação. Neste debate não se buscou o prolongamento, pois daria um outro recorte, o que ocasionaria outra pesquisa, o que se fez foi apontar alguns conceitos para mostrar os equívocos, que para alguns parecem a mesma coisa, assim tornam os conceitos naturalizados e sem a mínima relevância.

De acordo com Nilma Lino (2003) a questão de identidade negra é uma construção do negro dentro dos espaços sociais, da escola, ou seja, uma construção contínua durante o tempo que o indivíduo permanece interagindo com o meio social e escolar. Desta forma a escola como espaço de aprendizagem, tem a responsabilidade social e educativa nesse tema complexo que é construção da identidade negra positiva. 
Quando alguém diz ser negro ou torna- se negro dentro do Brasil, não só atém a cor da pele, essa é identidade negra. Essa construção tem que ser respeitada pelo agente educacional, pois ela consiste nas relações de poder no processo histórico do negro. É nesse processo que entendemos que a escola como um espaço de conflitos de olhares de enfretamento de opiniões, escola se torna um espaço de interferência na construção de identidade do indivíduo, seja de forma positiva ou negativa.

O que essencial que os projetos pedagógicos sejam formulados ressaltando a cultura afro brasileira, e também melhore o foco na formação dos professores, empenha-se para reparar os danos de cinco séculos, isso não quer dizer que esses projetos sejam só direcionados só para os negros, são para os brancos, indígenas e asiáticos também, pois somos uma sociedade brasileira. É necessário afirmar que a lei não venho para mudar a direção da história da raiz europeia para africana, a lei vem para qualificar melhor os agentes da educação e os professores, melhorar as relações sociais e econômicas, potencializar os currículos escolares. São metas vitais dentro da escola vão contribuir para valorização do indivíduo dentro do sistema escolar e a sua continuidade dessa construção positiva faz com que a diferença que é tão ressaltada se torne igualdade.

Em outras palavras, uma escola com equidade e sem diferenças com grupos étnicos raciais. Apesar de ter tido sérios debates sobre a raça, seja nas ciências sociais ou no movimento negro, a questão é de acordo com a Nilma Lino Gomes(2005,p.104), quando se fala do termo raça, é a forma com a qual essa palavra dá noção o quanto o racismo está engendrado e como o preconceito é enraizado na sociedade brasileira.

Neste sentido é relevante uma breve explanação de alguns conceitos diretamente ligados com a temática do ethos da população negra. Entender que o conceito de raça nesse processo histórico, conforme Nilma Lino Gomes (2005,p.105) nos destaca, é perceber que as construções sociais, políticas e culturais são relações de poder ao longo do processo histórico.

Adentrar-se-ia um pouco na origem do racismo e o sistema escravagista, para fazer uma reflexão sobre as práticas do racismo e mito da democracia racial dentro da esfera escolar, pois são algumas questões norteadoras para se entender como são os mecanismos dentro do processo da construção do indivíduo dentro e fora da escola, o que estas questões produzem e resultam na estrutura estruturante de uma sociedade.

O mito da democracia racial faz parecer que a questão é só econômica, pois perante a constituição somos todos iguais e no Brasil não existe racismo e nem segregação, portanto para alguns, os negros gozam de uma sorte, pois aqui não é igual aos Estados Unidos, África 
do Sul, não temos Apartheid! Apesar da maioria negra estar nas favelas, presídios e manicômios, isso não faz diferença.

Não é problema da sociedade brasileira. Muitos vão pensar assim. Mas o que deve ser compreendido, uma vez que a lei é para todos e não só de negros para negros. A banalização por parte de muitos profissionais que anteriormente em seus estudos, não tiveram o contato com a lei, reproduzem um desdém no processo de educar, e nesse aspecto só faz a lei entravar.

Na análise do etnólogo Carlos Moore (2007) sobre a lei 10639/03 o desafio maior está no professor, como o educador vai falar da história de um povo e de civilizações da África nas salas de aula se não tiver sensibilidade e empatia. Então ele terá que acabar com os preconceitos e estereótipos sobre o conteúdo dado. Terá que enfrentar novas reproduções do olhar hegemônico mundial que se declara por novas formas e que se legitimam com antigos preconceitos. Moore vai dizer que a lei 10639/03 não poderá destituir da historiografia própria dos africanos, sem lesionar seriamente a condição real cientifica implementada e validada.

$\mathrm{Na}$ argumentação dele, para se falar de África tem que partir de dentro que compromete uma conduta que vai além das expectativas inclusa na própria pesquisa. Que por sua vez se configura no entendimento criativo composto que caracteriza estabelecer as realidades sócios econômicas, cosmogônicas que se relacionam nas próprias estruturas, e isso ele vai chamar de conhecimento orgânico. O autor vai chamar atenção para as obras africanas, que ainda não estão traduzidas para o português e espanhol, é isso dificulta a distribuição na América Latina, e isso só ocorre em razão do mercado econômico e político das editoras e em consequência disso o risco, e de favorecer a tradução da língua portuguesa que são obras carregadas de preconceitos e desatualizadas pode ser um dos fatores que venha afetar nas avaliações das fontes de ensino para os professores.

Como catalogar a estruturas sociais e econômicas africanas, os modos de produção, desconstruir os dogmas que o desenvolvimento universalmente histórico da África foi linear. O autor analisa onde problemática está, qual é lugar que ocuparam essa antiguidade egípcia núbias até o XIX, quais foram as categorias de escravos servis, como foi o impacto sofrido nas formas diferentes de produção, e se existiu uma escravatura sem o sistema escravista, a forma de ocupação deixou um povo fadado a força de trabalho, um ser humano escravizando outro ser humano, seja qual for a maneira ou a forma, são relações que precisam ser avaliadas, o autor diz que aconteceu anteriormente e que acontece agora, mas sobre novas roupagens. Que o professor precisa lidar com empatia e sensibilidade, para lei 10639/03 desempenhe o seu papel. 
Na leitura de kabengele Munanga (2005) uns dos problemas que a lei encontra é o preconceito dos professores, e a falta de preparo, o que ele vai dizer o fato do professor ter feito uma graduação, não isenta de ele ter preconceitos, na verdade, pois muitos acham quem faz uma universidade, deixa-se de ser ignorante e logo este vai deixar de ser preconceituoso, e não é isso, este profissional não sabe lidar com as discriminações diárias do cotidiano escolar, porque as discriminações os preconceitos penetra nas relações sociais e no âmbito escolar, o professor por esta despreparado ele não percebe que a escola é um espaço que pode ser aproveitado para se debater questões pedagógicas e deixar de favorecer políticas que vão colocar alunos negros na defensiva e constrangidos.

Enfatizar que a diversidade não é condição de ser superior ou inferior, o que ela vai fazer e complementar maneiras de valorizar a humanidade geral, além disso ele vai fortalecer, ressaltar suas diferenças como formas de dignidade e orgulho e deixar de lado aquela forma negativa que antes fora inserida dentro do contexto.

\section{CONSIDERAÇÕES FINAIS.}

Sobre os professores, percebo que para trabalhar a lei 10639/03 dentro da escola se faz necessário passar pelo viés da cultura, forma que encontraram para aplicar a lei, mesmo que para trabalhar o conteúdo histórico precise cair no folclore, que não deixa de ser uma ação afirmativa. Já que esse é o caminho que os docentes conseguem aplicar a lei, porque não? Ainda assim, nestas escolas as ações dependem de alguns professores, não que isso não seja uma forma positiva. Deste modo, propor ao docente divisão do espaço e tempo dentro do âmbito escolar, em entender o processo do aluno e trabalhar a auto estima deste aluno. Até que ponto é necessário o resgate da história contribui analisar esse processo compreendendo todo processo histórico e entender as falhas, os equívocos históricos.

Os movimentos sociais e negros tiveram uma longa luta para conseguir alcançar a lei 10.639/03. É mais que fundamentado o desenvolvimento da lei e o crescimento da conscientização dos profissionais, deixar de lado o conflito de entre entender que a valorização não é folclorização.

Do modo que o aluno numa esfera de compreensão histórica, construir esse estudante possa ter olhar crítico nas coisas que sãos dadas.

É interessante entender a contribuição da cultura afro brasileira e como isso se torna um instrumento de conhecimento, entretanto o processo de construção de identidade do indivíduo é pautado na sua história escrita e narrada e o que dentro da escola é o espaço que a 
cultura é debatida e a sua particularidade é ressaltada.

Portanto, o indivíduo que não se identifica neste parâmetro, este individuo já entra em desvantagem quando ele tiver que disputar as representações no mundo social de hoje. Não conhecer sua história faz com que esse indivíduo esteja "fadado" a adentrar o processo de marginalização. Isso perpetua na família, escola e fora, porque a família, a escola são os lugares que reproduz os preconceitos e estes lugares em vez de desconstruir essa estrutura de racismo, preconceito e discriminação são os primeiros a promover e desenvolver essas práticas discriminatórias. Relevância da questão é criar possibilidades para que adote a lei no âmbito escolar ou seja qual é o entrave da lei

Alguns professores têm a boa vontade, mas caem na teia de começar um processo de conscientização e não conseguir terminar, que faz o docente achar que o seu trabalho não tem muito significado, ou seja, não tenha muito propósito.

Racismo, preconceito, discriminação racial são temas conflituosos paro o professor, que ainda não consegue lidar com esses temas, entretanto o professor precisa procurar formas alternativas para desfazer certos equívocos, esses são alguns entraves da lei, enquanto o professor não criar estratégias educacionais para desconstruir os preconceitos e racismo a legislação não atinge seu propósito.

O debate pedagógico sobre o racismo institucional colabora no processo de aceitação desses alunos negros e não negros, a reeducação auxilia na desconstrução do racismo. São orientações do professor que vão fazer a diferenças. Se o professor ou os agentes escolares não perceber complexidade da lei nada adianta. O professor poderá oferecer padrões pedagógicos, para que a legislação não tenha obstáculos. O método educacional prático, no dia a dia, para que a desconstrução do racismo, desigualdade e do mito da democracia racial seja de fato coisa do passado.

Esclarecer a história e cultura africanas e afro-brasileiras sem a banalização e naturalização, ter o reconhecimento da diversidade e da valorização e atender as demandas políticas na construção da identidade do aluno esse é um começo para combater o racismo dentro das escolas.

Como corpo discente se renova a cada momento, alunos saem da escola e outros que entram, logo há essa necessidade de se perpetuar as práticas pedagógicas em relação a lei. Em alguns colégios existem professores que conseguem com êxito aplicar a lei 10639/03 mesmo tendo alguns obstáculos no decorrer do ano, mas isso não são em todas as escolas.

Como mexer com lei sem falar da religião? Isso é um grande problema e um dilema trabalhar a lei sem que tenha que mexer com a questão religiosa, mais será que a lei 10639/03 
está vinculada a religião? Ou é uma outra de forma de racismo impercebível dizer que para dá a cultura afro brasileira é preciso falar de religião? E se falar já que na constituição brasileira o país é laico. Entre essas e outras o professor precisa encontrar novos projetos pedagógicos para poder acabar com discriminação. Resistência dentro do espaço público, principalmente quando este se refere a religião, entretanto ele com seu trabalho, atuando e aplicando a lei e fazendo para que a legislação contribua na construção dos indivíduos dentro do âmbito escolar.

Conforme fui entrevistando as professoras percebo o que faz mais tênue dentro da legislação, é quando aborda sobre a religião, esse é ponto fragilizado da lei. Apesar do espaço ser laico as pessoas operam de uma maneira como só fosse permitido falar sobre o cristianismo e catolicismo, se não for assim, fica á margem da história.

Em algumas escolas a aceitação por parte dos agentes e dos professores é mais fácil. A escola também tem o seu papel de desarticular o racismo, apesar de não ser exclusivamente da escola este papel, mais o foco fica mais claro ali, já que as discriminações perpassam dentro da esfera escolar.

O parecer da lei propõe alternativas com respostas, explicações, para os professores e sociedade. Procura atender as demandas das instituições para implementação da lei. Sobretudo sendo mais efetivo na área da educação, na luta contra o racismo, preconceito, desigualdades, políticas de reparações de reconhecimento e valorização de ações afirmativas.

As metas em relação a educação das relações ètnico- raciais no parecer vai depender de um conjuntos de fatores para ele alcance o sucesso e o reconhecimento. Mas se o professor não estiver ciente disso, a interpretação da lei vira um entrave, pois ele só vai entender no art. Art.26 A da lei 10639/03 que é posto oferecer o ensino da história da África e cultura afro brasileira. A lei visa criar condições sobre o poder de decisão na sociedade, se não entendido deste jeito será um outro desafio.

Até o presente momento da análise da pesquisa referida, conclui -se que temos fatores primordiais, que nos levam aos entraves da prática pedagógica em se fazer uma discussão mais embasada da historicidade dos africanos e os seus descendentes da diáspora ( lei 10639/03). Fatores que são os entraves que impossibilitam os projetos pedagógicos: A rotatividade de alguns profissionais da educação, com isso ocorre uma ruptura do projeto pedagógico que antes estava sendo desenvolvido dentro da escola, ou profissional então leva o projeto pedagógico para outra escola. 
Se a escola anterior não estiver envolvida coletivamente no decorrer do ano, está ficará sem projeto pedagógico, a gestão da escola também é outro fator. A lei fica dependência com muita frequência de iniciativas de ações isoladas de alguns profissionais, não que seja bom, mas não é o ideal, a inviabilidade dos planos políticos e pedagógicos faz a lei atravancar, a falta de sensibilidade, empatia e o comprometimento por parte do professor com ensino da história da África e cultura afro brasileira, é o outro entrave.

O estado, a gestão da escola também têm o compromisso e a responsabilidade de criar condições de vivencias e possibilidades para que a legislação se efetue de fato. A produção do conhecimento possibilita diálogos, discussões na luta anti racista. Um caminho longo nessa construção social, cultural e política onde os atores são os negros e o debate nas relações étnicas raciais é inevitável. Novos processos pedagógicos em relação ao currículo e o ensino das relações étnicos raciais, proporcionando um diálogo multicultural.

Quando falamos de Brasil, tocamos no ponto chave para se e compreender a complexidade da aplicação e efetivação da lei em função da diversidade do país ( Não existe nenhum outro país fora do continente africano onde a uma mistura étnica tão grande como no Brasil) e também a função do epistemicídio cultural e desse conhecimento universalista que nos é implementado qual temos o tempo todo estar atento e aprender.

Quando se precisa fundamentar uma lei 10639/03 para reparações de um povo descendentes de escravizados é um entrave. Modificar a estrutura da educação na sociedade brasileira é um desafio não só dos professores e agentes da educação, a sociedade brasileira também, porém quando se mexe com a educação é o mesmo que mudar a estrutura de uma sociedade elite excludente que se julga sem preconceitos e democrática, modificar a forma de pensar é mudar de postura, dá novo significado a história da África e do Brasil que não é tarefa fácil.

A sociedade fica temerosa quando se trata de transformação, a lei 10639/03 venho para produzir conhecimentos e socializar e dá visibilidade para o campo de debate das relações étnicos raciais. Na fala da professora Petrolina, no programa, num balanço sobre a lei 10639/03, ela diz: "aonde chegamos com a lei e para onde temos que ir" que é colocar práticas pedagógicas e outros conceitos de cultura em diálogo tem que acontecer de fato na produção de conhecimento, não é colocar um povo superior ao outro, e submeter a reflexão da história da África e da cultura afro brasileira, que no decorrer do tempo ela venha ser propagada. 
Isso é um grande entrave para lei, pois a legislação e o parecer fala de reconhecimento, valor, racismo, preconceito, mito de democracia racial, discriminação, desigualdades são conteúdos que vão provocar novas posturas e os professores precisam estar preparados para dá o ensino da africanidade, ensinar a visão do mundo sem separar da espiritualidade, esse foi dos fatores colocado como mais um dos entraves, pois nas entrevistas foi abordado a rejeição por parte dos alunos, quando se toca na religiosidade .

Valorizar a oralidade de um povo sem esquecer da língua escrita, porque a escrita é poder, o professor não está preparado para fazer o diálogo das culturas e manter o pertencimento étnico independe da cor dele ou da sua crença, desse modo o professor pode sugerir novas possibilidades de ensino, já que ele tem poder da avaliação, inclusive tem o poder transformar o currículo, além do mais a maioria acha que a lei é uma forma de enaltecer a África e desmerecer o ocidente, ou seja, não é uma cultura sobrepor a outra senão estaríamos fazendo democracia racial com uma nova roupagem e não é isso, o professor precisa perceber as diferenças, olhar o outro com respeito e criar condições para um diálogo.

Parto do pressuposto que ensinar a história da africana e cultura brasileira, não necessáriamente precisa basear no pensamento africano e sim no nosso cotidiano.

A grande maioria tem esse pensamento em relação da lei, ter a dificuldade de transmitir o conhecimento da lei sem lê os PCNS ou (Diretrizes Curriculares Nacionais) DCNS, o professor precisa ter o conhecimento dos pareceres, em outra fala de Nilmo Lino no programa balanço sobre a lei 10639/03.

Para a desigualdade e a exclusão ser justificada é preciso ter uma política pública, então a lei 10639/03 e vem para o cenário político social brasileiro para legitimar as falhas do estado, entretanto se isso não for entendido por parte dos professores e dos agentes da educação e a sociedade brasileira, a lei continuará com seus entraves.

\section{REFERÊNCIAS}

BRASIL. Ministério da Educação/ Secretaria da Educação Continuada, Alfabetização e Diversidade. Diretrizes curriculares nacionais para a educação das relações étnico-raciais e para o ensino de história e cultura afro-brasileira e africana na educação básica. 2004.

BRASIL. Ministério da Educação/Secretaria da Educação Continuada, Alfabetização e Diversidade. Educação Anti-Racista: caminhos abertos pela Lei Federal nº10. 639. Brasília: SECAD, 2005. 
BRASIL. Ministério da Educação/Secretaria da Educação Continuada, Alfabetização e Diversidade. Orientações e Ações para a Educação das Relações Étnico-Raciais. Brasília: SECAD, 2006.

COSTA, Sérgio. A construção Sociológica da raça no Brasil. Estudo afro-asiáticos. Ano 24, $\mathrm{n}^{\mathrm{o}} 1$, pp.35-61.

GOMES, Nilma Lino. Educação e Identidade Negra. Belo Horizonte, 2002. Disponível em: http://www.letras.ufmg.br/poslit.

GOMES, Nilma Lino. Cultura Negra e Educação. Revista Brasileira de Educação. n²3 Rio de Janeiro, Maio/Agosto. 2003.(Obra completa)

GOMES, Nilma Lino. Educação e Relações Raciais: Refletindo sobre Algumas Estratégias de Atuação. In: MUNANGA, Kabengele (Org.). Superando o racismo na escola. Brasília: Ministério da Educação, Secretaria de Educação Continuada, Alfabetização e Diversidade, 2005.p.98- 108 .

Hooks, Bell: Ensinando a Transgredir: A Educação Como Prática da Liberdade:

Martins Fontes, 1994 288p (Obra completa)

LÓPEZ, Laura Cecilia. O conceito de racismo institucional: aplicações no campo da saúde. Comunic., Saúde, Educ., v.16, n.40, p.121-34, jan./mar. 2012.

MOORE, Carlos. Racismo e Sociedade: novas bases epistemológicas para entender o racismo. Belo Horizonte: Mazza, 2007. (Obra completa) 